\title{
ROMANEN UND BAJUWAREN IM INNTAL
}

\author{
ROMANEN AND BAJUWAREN IN INNTAL
}

\author{
Andrzej Michałowski \\ Instytut Prahistorii, Uniwersytet im. Adama Mickiewicza \\ Św. Marcin 78, 61-809 Poznań, Poland
}

ABSTRACT. On the basis of available archaeological. historical, and linguistic evidence the article presents an overview of the beginnings of Inn valley (northern Tirol) population at the turn of antiquity and in the early phase of Middle Ages by German tribe of Bajuwaren. It further considers a reciprocal coexistence of these immigrants from beyond the Alps with local post-Roman groups of Breones. A peaceful coexistence, common religion (Catholicism) and external threat from Alamans, Longobards and Slavs led in a long run to the cultural and linguistic assimilation of Roman groups by Bajuwaren.

Dieser Aufsatz wurde vom Verfasser während seines Aufenthalts im Institut für Vor- und Frühgeschichte der Ludwig-Maximilian-Universität in München geschrieben, wo er, im Rahmen des ihm erteilten Stipendiums, das Hauptseminar von Prof. Dr. Volker Birbrauer „Archäologie und Geschichte des mittleren und östlichen Alpenraums in Spätantike und Frühmittelalter (4.-8. Jh.)" besuchte. Der Aufsatz wurde am 30.07.1998 in diesem Seminar präsentiert.

Hiermit möchte sich der Verfasser bei Herrn Prof. V. Birbrauer für die Unterstützung und alle Hinweise recht herzlich bedanken. Der Autor möchte auch seinen herzlichen Dank Herrn Stefan Biermeier M.A. für die sprachliche Hilfe aussprechen.

\section{EINLEITUNG}

„Romanen” war die Eigenbezeichnung der Bewohner des Imperium Romanum. Die Bewohner des Tiroler Inntales und seiner Seitentäler wurden im 1. Jh. als Berunen, später als Breonen bezeichnet. Strabo nennt die Breuni als ein mit den Rätern verwandtes Volk. Die romanisierten Breonen scheinen in den Quellen aber auch südlich des Brenners im Eisacktal auf ${ }^{1}$. Unabhängig von ihrer ursprünglichen

\footnotetext{
${ }^{1}$ Lippert 1989, S. 69.
} 
ethnischen Zugehörigkeit können sie nach Provinzialisierung und Romanisierung als Romanen angesehen werden. Das Romanenbewußtsein wird besonders deutlich im 5. Jh., als germanische Stämme in die Gebiete des ehemaligen Imperiums eindringen und die eroberten Gebiete besiedeln. Kontakte zwischen Romanen und Germanen waren keineswegs eine neue Erscheinung. In starkem Gegensatz etwa zu der zunehmenden „Germanisierung” des römischen Heeres stehen aber die in der Völkerwanderungszeit einsetzenden dauerhaften Landnahmen germanischer Stämme auf römischem Gebiet. Innerhalb der neu erstehenden germanischen Reiche - etwa das Ostgoten- und Langobardenreich - waren die Romanen zahlenmäßig bei weitem in der Überzahl.

Die Bajuwaren - in den lateinischen Schriftquellen als Baibari, Baiobari oder Baioarii bezeichnet - haben für ihre Frühzeit keinen Geschichtsschreiber. Die erste Nennung geht auf den gotischen Chronisten Jordanes zurück, der im Jahr 551 eine Geschichte des gotischen Volkes fertiggestellt hatte. Dabei kommt er auch auf einen Krieg zu sprechen, den die Goten im Winter $469 / 470$ gegen die Sueben führten. Jordanes schreibt zunächst: Als der Gotenkönig (Theodemir) sah, daß die Donau zugefroren war, führte er sein Fußvolk über den Fluß und erschien überraschend im Rücken der Sueben. Denn jenes Land der Sueben hat im Osten die Bajuwaren, im Westen die Franken, im Süden die Burgunden und im Norden die Thüringer zu Nachbarn. Jordanes hat seine Gotengeschichte zu einem großen Teil von einer Vorlage Cassiodors abgeschrieben. Das Werk Cassiodors De origine actibusque Getarum, in dem der Bajuwarenname bereits Erwähnung gefunden haben dürfte, entstand um $519 / 522^{2}$.

Der Name Bajuwaren setzt sich aus zwei Teilen zusammen. Die Endung -varii bedeutet „Männer aus”, während Baio die geographische Herkunft bezeichnet, die auf Böhmen - das Boiohaemum - verweist ${ }^{3}$.

Von historischer Seite wird heute die Theorie einer bajuwarischen Ethnogenese unter gotischer Ägide favorisiert, die in die Zeit fällt, als Theoderich auf der Höhe seiner Macht stand und das nördliche Alpenvorland einigermaßen zu kontrollieren vermochte. Die Ostgoten befanden sich zu dieser Zeit (507) im Krieg gegen Franken und Burgunder. Die Verbindung zu den Thüringern und der Weg der ständig hin und her ziehenden Gesandtschaften führte jedoch über das rätische Flachland, und es liegt auf der Hand, daß Theoderich hier mehr als anderswo daran interessiert war, ein mögliches Vakuum zu überbrücken und keine Lücke entstehen zu lassen, in die von Westen die Franken, von Osten die Longobarden hätten eindringen können. Theoderich mußte also darauf bedacht sein, einen Prozeß der Ethnogenese in diesem Raum, der vielleicht schon im Gange war, in seinem Sinne durch die Ansiedlung von Zuzüglern aus dem böhmischen Raum zu fördern ${ }^{4}$.

\footnotetext{
${ }^{2}$ Reindl 1988, S. 56, 57.

${ }^{3}$ Reindl 1988, S. 57.

${ }^{4}$ Lotter 1985, S. 56, 57.
} 
Archäologisch sind mehrere Wellen alamannischer - erster Zuzug bald nach der Mitte des 5. Jhs. - und langobardischer (und thüringischer) Zuzügler - seit dem späten 5. Jh. - nachweisbar ${ }^{5}$.

Der Zeitpunkt für die bajuwarische Ethnogenese fällt mit der langobardischen Einwanderung ins Rugiland zusammen. Böhmische Germanen könnten jedenfalls solche „Leute aus Böhmen” gewesen sein, die in die voralpine Raetia II auswichen, als der Großteil ihrer Stammesgenossen. Als Kern der bayerischen Ethnogenese gilt derzeit der Raum von Regensburg und Straubing ${ }^{6}$.

Von Bedeutung ist nach $\mathrm{H}$. Wolfram, daß das Reich Theoderichs nicht durch eine Grenze, sondern durch einen dreifach gegliederten, breiten Grenzsaum abgeschirmt war. Die erste Verteidigungslinie bestand aus Befestigungen an den Südausgängen der Alpen - ostgotische Truppen; zweite Linie - inneralpine Zone - Föderaten. Für den rätischen Westen ist der Dux Raetiarum Servatus bezeugt. Er vereinigte die militärische wie zivile Verwaltung in seiner Hand und befehligte nicht năher bezeichnete „Soldaten”, milites, die Theoderich als Einheiten seines Heeres ansah. Die rätischen Truppen rekrutierten sich wohl aus der einheimischen Bevölkerung, während den Breonen ohnehin die militaria officia bescheinigt wurden ${ }^{7}$. Die Bajuwaren bildeten in diesem System die dritte Verteidigungslinie.

Auf jeden Fall war der Name des bajuwarischen Stammes spätestens im 3. Jahrzehnt des 6. Jahrhunderts so bekannt, daß er neben den Thüringern, Franken und Burgunden genannt werden konnte ${ }^{8}$.

\section{BAJUWAREN IM INNTAL}

Der Inn durchfließt auf seinem Weg nach Norden die Alpen, wo er ein großes Tal - das Inntal - schafft. Das Inntal liegt zwischen Lechtaler Alpen, Wetterstein Gebirge und Karwendel Gebirge im Norden und Ötztaler Alpen, Stubaier Alpen und Tuxer Alpen im Süden.

Das Inntal wurde während des augusteischen Alpenfeldzugs 15 v. Chr. von Rom besetzt und noch vor Mitte des 1 . Jhs. n. Chr. als römische Provinz Raetia organisiert. Die Provinz Raetia war $80000 \mathrm{~km}^{2}$ groß und umfaßte die Südostschweitz, Vorarlberg, Tirol, große Bereiche der Zentralalpen sowie das Alpenvorland zwischen Bodensee, Donau und Inn. Begrenzt wurde Raetien im Norden von der Germania Magna (raetischen Limes), im Westen von der Provinz Obergermanien und Provinz Alpes Graiae et Poeninae, im Süden vom italischen Mutterland und im

\footnotetext{
${ }^{5}$ Bierbrauer 1985, S. 21-25.

${ }^{6}$ Wolfram 1985, S. 105-109.

${ }^{7}$ Wolfram 1979, S. 391, 392.

${ }^{8}$ Lotter 1985, S. 57.
} 
Osten von Provinz Noricum ${ }^{9}$. Diese Form der Organisation wurde im Rahmen der Reformen Diokletians modifiziert.

Mit der Teilung Noricums unter Diokletian (267) kommt das mittlere Eisacktal zu Raetien. Wenig später wurde unter Constantin I. auch Raetien in die Provinzen Raetia I. und II. geteilt. Raetia II. setzte sich aus dem Flachland zwischen Iller und Inn, Nordtirol, dem Vintschgau und dem mittleren Eisacktal zusammen. Raetia II. behielt Augusta Vindelicorum (Augsburg) als Hauptstadt ${ }^{10}$.

Beide Verwaltungseinheiten gehörten zur Präfektur Italien und zur Diözese Italia annonaria, der ein vicarius mit Sitz in Mailand vorstand. Jede der beiden raetischen Provinzen wurde von einem eigenen Zivilbeamten mit Titel praeses verwaltet ${ }^{11}$.

Der Heerführer des Weströmischen Reiches - Aetius - vertrieb um 430 zum letzten Male die einbrechenden Scharen, bis nach seinem Tod 454 das Alpenvorland endgültig verlorenging. Die beiden Provinzen verblieben im Reich Theoderichs des Großen (473-526). Um 545 eroberten die Franken Raetia I. ${ }^{12}$

Venatius Fortunatus und Secundus von Trient benutzten zur Bezeichnung des mittleren Nordtirols nicht mehr den alten Provinznamen Raetia Secunda, sondern den Landschaftsnamen Beronium, bzw. regio Brionum ${ }^{13}$. Diese Gebiete wurden durch die Bajuwaren besetzt.

Aus der Beschreibung seiner Wallfahrtsreise, die Venantius Fortunatus, der spätere Bischof von Poitiers, im Jahre 565 unternahm und die ihn von Ravenna nach Tours zum Grab des heiligen Martin führte, erfahren wir, daß der aus Venetien stammende Dichter auf seiner Rückreise mit einer Behinderung durch die Baiern erst im Gebiet des nördlichen Alpenraumes rechnete. Dies dürfte darauf hinweisen, $\mathrm{da} ß$ zumindest das westliche Oberinntal zu dieser Zeit von Bajuwaren noch nicht besetzt war $^{14}$. Dann bemächtigten sich die Bajuwaren in der Zeit zwischen etwa 565 und 595 des Landstrichs zwischen Ziller und Habach. Jedenfalls auch des Sill sowie östlichen Oberinntals, wofern dieses nicht schon in ihrem Besitz war. Vielleicht haben sie den im Jahr 590 ausgefochtenen Krieg zwischen Franken und Langobarden dazu benützt, in das mittlere Nordtirol und das obere Eisacktal vorzudringen. Fest steht nur, daß sie im Jahr 592 den Weg, der über jenen $\mathrm{Pa} ß$ nach Süden und vom Brixener Becken ins Pustertal führt, bereits in bajuwarischer Hand gehabt haben müssen ${ }^{15}$.

Im Jahre 592 unternahmen die Bajuwaren unter Führung ihres Herzogs Tassilo einen Feldzug gegen die Slawen, die den östlichen Teil des Pustertals besetzt hiel-

\footnotetext{
${ }^{9}$ Dietz 1995, S. 18.

${ }^{10}$ Krinzinger 1972, S. 13.

${ }^{11}$ Fischer 1995, S. 361.

${ }^{12}$ Krinzinger 1972, S. 13.

${ }^{13}$ Heuberg 1932, S. 148.

${ }^{14}$ Plank 1964, S. 134.

${ }^{15}$ Heuberger 1932, S. 143, 144.
} 
ten. Dieses Unternehmen war von Erfolg gekrönt und erbrachte reiche Beute. Weniger glücklich verlief der einige Zeit später durchgeführte Versuch der Bajuwaren, die Slawen aus dem Pustertal zu verjagen und sich des Gebietes zu bemächtigen. Sie wurden dabei ungefähr 600-610 von den Awaren bei Arguntum besiegt. Der Herzogssohn Garibald (Grimoald) fiel in der Schlacht und viele bajuwarische Krieger fanden den Tod. Seit dieser Zeit, als die bajuwarischen Truppen im Pustertal operierten, hat sich jedenfalls Nordtirol in ihrer Hand befunden ${ }^{16}$.

\section{ARCHÄOLOGISCHE QUELLEN UND PROBLEM DER ETHNISCHEN SONDERUNG ZWISCHEN ROMANEN UND BAJUWAREN}

Einen Beitrag zur Besiedlungsgeschichte des Inntales im frühen Mittelalter können von archäologischer Seite in erster Linie die siedlungsindizierenden Gräber liefern, da nur wenig verwertbare Siedlungsgrabungen vorliegen. Aus diesem Grunde ist es nötig, zunächst romanische und germanische Grab- und Bestattungssitten zu charakterisieren.

Kennzeichnend für Gräber einer romanischen Bevölkerung sind: Waffenlosigkeit der Mănnergräber und die Häufung genuin romanischer Einzelkriterien an einen Fundplatz:

1. Die überwiegende Beigabenlosigkeit bzw. reduzierte Beigabensitte.

2. Mit Steinen und/oder Platten umfaßte und abgedeckte Gräber und auch Sarkophage mit oder ohne Christogrammen.

3. Mehrfachbestattungen in einen Plattengrab oder Sarkophag.

4. Die genuin romanisch-mediterrane Einfibeltracht der Frau, wobei die Fibel in Brustmitte einen Mantel oder mantelartigen Umhang verschlo $\beta^{17}$.

Typisch für bajuwarische Gräber sind:

1. Reihengräberfelder mit z.T. sehr tiefen Grabgruben. Auf der Grabshole stand der Sarg, genauer ein Grabeinbau aus gefugten Brettern ohne Metallbeschläge, auf zwei Unterlagsbalken. Daneben waren auch Baumsärge üblich, die mit zwei großen Dübeln verschlossen wurden.

2. Tuffplattengräber - die Grabshole und alle vier Seiten des Schachtes war mit sorgfältig zugerichteten Tuffplatten ausgekleidet. Bei Tuffplattengräbern handelt es sich um eine spätmerowingische, noch bis in das 8. Jahrhundert hinreichende Grabform.

3. Reiche Beigabensitte: Männer wurden mit ihrer Waffenausrüstung, bestehend aus Sax, Spatha, Lanze, Schild und etwa Bogen bestattet. Dazu konnten als echte Beigaben Trensen und Pferdegeschirr, Trinkgeschirr, Speisebeigabe, Toilettgerăt

\footnotetext{
${ }^{16}$ Plank 1964, S. 134.

${ }^{17}$ Bierbrauer 1994, S. 153.
} 
und selbst Sitzmöbel kommen. Frauen wurden in ihrer Tracht (zunächst Vierfibeltracht) bestattet. Am Gürtel befestigte Amulettgehänge sind zahlreich vertreten. Daneben fanden sich auch verschiedene echte Beigaben in den Gräbern ${ }^{18}$.

\section{DIE SPÄTANTIKE ROMANISCHE BESIEDLUNG IM INNTAL}

Eine zusamenhängende romanische Besiedlung im Inntal gab es zwischen der Melch im Westen und dem Achensee bzw. Ziller im Osten ${ }^{19}$. Konkrete Siedlungsreste aus dem Inntal des 4. Jhs. sind aus dem Lager und der Siedlung von Veldidena und vom Martinsbühel bei Zirl bekannt. Weitere Befunde sind seit kurzem in der Gemeinde Kematen bezeugt. Im frühen 5. Jh. wurden mehrere Kirchen im Inntal errichtet. Größe, Form und Innenausstattung dieser in Stein gebauten ältesten Kirchen lassen eine deutliche Beziehung zum Patriarchat in Aquileia, das die ostalpine Bistümer betraute, erkennen. Solche Kirchen sind in Imst, Pfaffenhofen, am Martinsbühel bei Zirl, in Ampaß, Stans und in Thaur errichtet worden ${ }^{20}$.

1. Imst. Unter der Laurentiuskirche in Imst (Abb. 1A) konnte ein frühchristlicher Vorgängerbau nachgewiesen werden. Gefunden wurden Reste der Nord- und Westmauer, der westliche Teil des Bemas, die Solea und der für Reliquien bestimmte Loculus. Zwischen den Längswänden des $5,75 \mathrm{~m}$ breiten Schiffes und dem Bema lag im Norden $1 \mathrm{~m}$ hinter dessen Vorderkante ein $35 \mathrm{~cm}$ schmales Mäuerchen, das Fundament einer weiteren Schranke. Das anzunehmende Pendant im Süden ist wegen der leicht asymmetrischen Lage des Bemas von der romanischen Ostmauer zerstört worden. Das im Lichten 2,6 m breite Bema war im Norden, Westen und Süden von einem $50-60 \mathrm{~cm}$ starken Fundament begrenzt, das die vermutlich gemauerte Chorschranke trug. Der östlische Abschluß der frühmittelalterlichen Kirchen ist nicht erhalten. Die Länge des Schiffes bis zur Vorderkante des Bemas beträgt 7,6 m. Von der ingesamt $2,2 \mathrm{~m}$ langen und im Lichten $50 \mathrm{~cm}$ breiten Solea waren auf drei Seiten 30-35 cm starke Fundamente der Schranken erhalten. Der etwa in Mitte des Bemas liegende Loculus war $90 \times 90 \mathrm{~cm}$ groß und ursprünglich tonnengewölbt. Im Westen schloß sich ein $1,25 \mathrm{~m}$ hoher, $60 \mathrm{~cm}$ langer, im Osten ein $45 \mathrm{~cm}$ breiter und sich trichterformig nach Westen erweiterenden Gang an, dessen Vorderteil nicht erhalten war. Über dem Reliquiengrab lag in situ eine ca. $1 \times 1 \mathrm{~m}$ große Marmorplatte, deren Mitte ein reliefertes Monogrammkreuz schmückte, während sich an den Ecken quadratische Ausnehmungen für die Beine eines Tischaltares befinden. Im Vergleich zu anderen frühchristlichen Kirchen aus Nordtirol ist die vom Kalvarienberg in Imst auffallend klein. Sicher gab es im schon 763 als oppidum bezeichneten

\footnotetext{
${ }^{18}$ Zeller 1988, S. 229-236.

${ }^{19}$ Lippert 1993, S. 11.

${ }^{20}$ Lippert 1989, S. 71.
} 


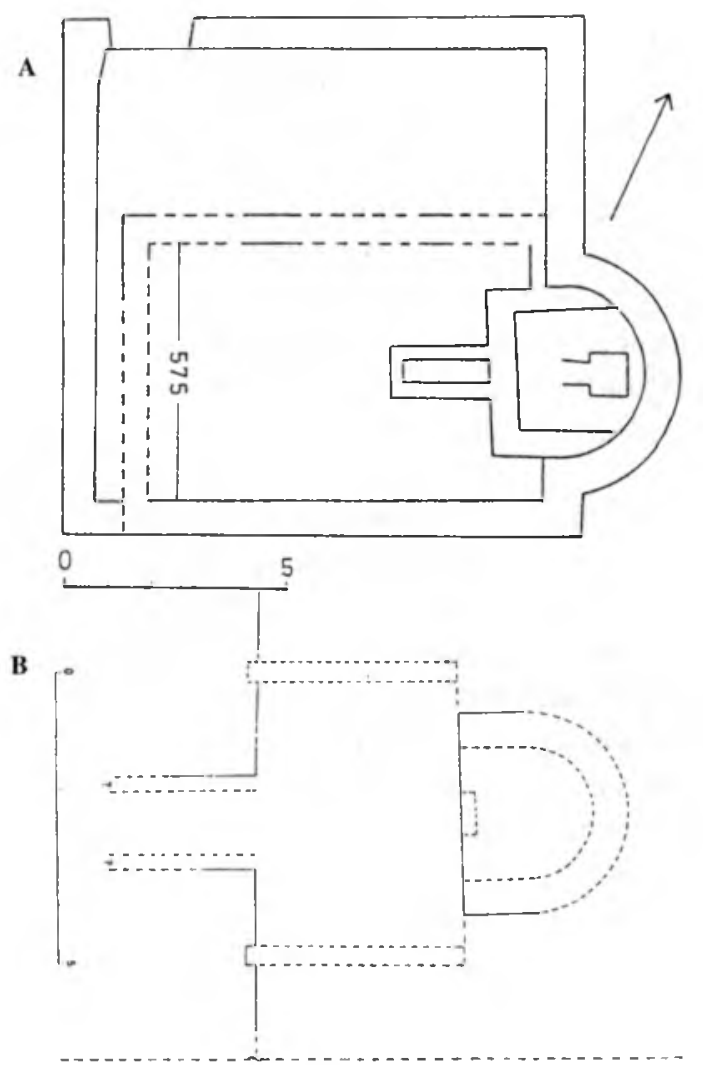

Abb. 1. A - Imst, Laurentiuskirche; B - Thaur, Pfarrkirche. Presbyterium der 1. frühchristlichen Bauphase. Rekonstruktionsversuch. Ergänzte Teile im unterbrochenen Strich (nach Sydow 1990)

Imst (Humiste) wegen seiner Lage auch im 5. und 6. Jh. bereits eine größere Kirche, die unter der heutigen, der Himmelfahrt Mariens geweihten, zu vermuten ist ${ }^{21}$.

2. Pfaffenhofen - siehe Kapitel V.

3. St. Martinsbühel. Zum ältesten Baubestand gehört die außen rechteckig ummauerte Apsis von 4,6 m lichter Breite und 3,6 m Tiefe, an die sich im Süden ein leicht eingetiefter Raum schloß. Von dem $8 \times$ durchschnittlich 13,6 m großen Saal gehört ein Teil der Südwand zum ursprünglichen Bestand, wobei dies für die übrigen Mauern nicht nachgewiesen ist. In die Rundung der Apsis und auf den Estrich wurde eine gemauerte Priesterbank mit Kathedra gesetzt. In der Sehne der Apsis befand sich eine Stufe, die teilweise eine $25 \mathrm{~cm}$ tiefe, ovale, wohl zu Recht mit Reliquiendeposition in Zusammenhang gebrachte Grube überlagerte. Vor dem nördlichen Schenkel der Priesterbank wurde ein Fundamentrest ergraben, der zum Unter-

${ }^{21}$ Sydow 1990, S. 26, 27. 
bau des Bemas gehört haben könnte. Es läßt sich nicht sicher beweisen, daß der Bau auch schon in der ersten Phase sakrale Funktion hatte. Gegen diese Vermutung spricht die rechteckig ummauerte Apsis, eine Form, die für frühchristliche Kirchen des Alpenraumes sonst nicht belegt ist, während sie in der spätkaiserzeitlichen $\mathrm{Pa}$ last-, Villen- und Thermenarchitektur öfter vorkommt. Der Einbau der Priesterbank muß nach bisherigem Wissen spätestens im 6 . Jh. erfolgt sein, so daß eine ursprünglich profane Funktion des Baus möglich erscheint. Handelt es sich beim St. Martinsbühel um das in der notitia dignitatum genannten Teriolis, waren in diesem im 4./5. Jh. vielleicht befestigten Stützpunkt nahe des römischen Innüberganges zwei für Nachschubwesen und germanischen Hilfstruppen verantwortliche Offiziere stationiert $^{22}$.

4. Ampass. Von der ersten Anlage haben sich nur die Reliquiengruft und Teile des ältesten Estrichs erhalten. Besonders wichtig war die sehr gut erhaltene Memoria, zu der ein $128 \mathrm{~cm}$ langer, 56 breiter und 117 hoher Schacht mit zwei Stufen im Westen gehört (Abb. 2B). Dort stand ein Memorienschrein, der die Form eines spätantiken Sarkophages hatte und in der ursprünglich das Reliquiar geborgen war. Eine Parallele zur Memoria von Ampass fand sich in der Kirche von Säben. In einer zweiten Phase wurde ein neuer Mörtelboden auf starker Rollierung eingebracht (Abb. 2A), in dem seichte Abdrücke von hölzernen Chorschranken erhalten waren. Das sich nach Osten leicht erweiternde Bema hatte am Westende eine lichte Weite von 4,41 m. In Achse lag die ebenfalls abgeschrankte, 1,23 m breite Solea, deren Länge wegen Störung durch ein neuzeitliches Grab nicht festgestellt werden konnte. Die Breite der Kirche hätte demnach ca. $8 \mathrm{~m}$ betragen ${ }^{23}$.

5. Thaur. Erhalten sind der vordere Teil einer $3,4 \mathrm{~m}$ breiten freistehenden Priesterbank, die 2 Stufen über dem viermal in Größe und Aufteilung veränderten Bema lag (Abb. 1B). Die Schranke wurde später nach Westen verlegt. Das Presbyterium hatte eine lichte Tiefe von 3,3 m. Die nur in Ansatz erhaltene Solea hatte eine lichte Breite von 1,11 m. Das Bema lag um eine Stufe höher als der Boden im Schiff. Über dem Altar erhob sich ein Ziborium ${ }^{24}$.

Alle frühchristlichen Kirchen im Inntal sind Saalbauten mit geradem Abschluß oder mit eingezogener halbrunder Apsis im Osten. Im Chor befanden sich freistehende oder an die Apsis angeschmiegte Priesterbänke, meist mit einem erhöhten Mittelsitz (cathedra) für den ranghöchsten Priester. Die Kirche und damit auch Siedlungen am Kalvarienberg bei Imst, am Martinsbühel bei Zirl und am Kirchhügel von Ampaß befanden sich unmittelbar an wichtigen antiken Verkehrsstraßen. Für diese Gebiete kann man nicht von Rückzugssiedlungen sprechen. Die höher und abseits gelegenen Plätze am Burgstall bei Arzl im Pitztal oder am Sonnenburger Hügel bei Natters dürften im 5. oder 6. Jh. wohl nur den Charakter von zeitweilig aus-

\footnotetext{
${ }^{22}$ Sydow 1990, S. 28, 29.

${ }^{23}$ Sydow 1990, S. 29.

${ }^{24}$ Sydow 1990, S. 30.
} 

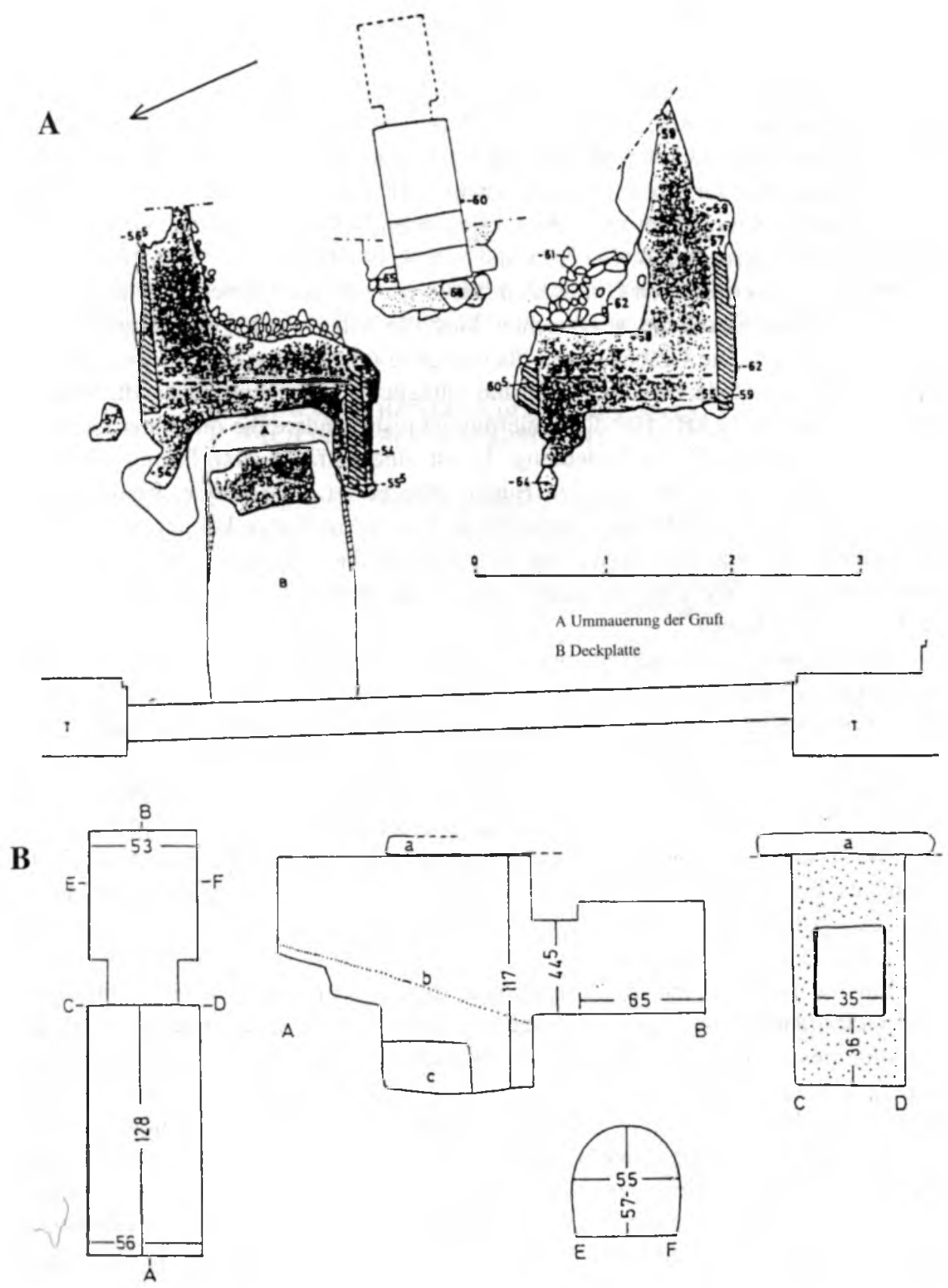

Abb. 2. Ampass. A - 2. Phase. Estrich gerastert, Bettung der Bemaschranken schrafiert. B - Plan und Schnitt der Memoria (nach Sydow 1990) 
gesuchten Fluchtburgen und nicht von castra oder castella wie anderswo gehabt haben ${ }^{25}$.

Zwischen 1979 und 1988 wurden am Südoststrand von Terfens, das auf der nördlichen hohen Inntalterasse vis-à-vis von Weerberg liegt, insgesamt 19 Gräber am Südrand einer ursprünglich größeren Nekropole entdeckt (Abb. 8A). Die NordwestSüdost orientierten Gräber sind insgesamt in einer Zeile angeordnet. Einzelne Grabschächte davon sind jedoch mit dahinter liegenden Gräbern zu kleinen Grabgruppen zusammengeschlossen (z.B. Gr. 7, 11 und 6, 5, 9, 14, 10 und 13, 15, 12, 16 und 17).

Manche dieser hinteren Grabstätten waren quer zu den Gräbern der letzten Reihe, also in West-Ost-Lage, ausgerichtet. Fast alle Toten wurden in gestreckter Ruikkenlage bestattet. Die Grăber waren überwiegend beigabenlos. Nur in wenigen fanden sich Gegenstände, die als Tracht und alltägliche Ausrüstungsbestandteile anzusprechen sind (Abb. 8B). Für die Datierung ist insbesondere die quadratische Eisenschnalle aus Grab 14 von Bedeutung. Es ist eine einfache drahtförmige Schnalle (Abb. 8B: 8), deren Dorn um den Bügel gebogen ist. Alle Seiten, besonders die Längsseiten, sind ,leierförmig” eingedrückt. Der Schnallentyp kommt während des gesamten 7. Jhs. vor. Ein zweiter Anhaltspunkt für die Datierung gibt die Radiokarbondatierung des Skelettes aus Grab 2, die ein ungefähres Datum zwischen 640 und 680 bestimmen lassen ${ }^{26}$.

Mancherorts weisen verschiedene Überlegungen und Funde auf eine weitgehende romanische Platzkontinuität hin. In Wilten - Veldidena z.B. ist ein frühchristlicher Vorgängerbau der heutigen Laurentiuskirche zu vermuten. Das LaurentiusPatrozinium deutet nämlich meist auf eine sehr frühe Entstehung hin. So gehören die in Imst, Stans und Wattens freigelegten Kirchen noch in das 5. bzw. 7. Jh. In Wilten kamen außerdem etwas östlich der Stiftskirche Grabfunde zutage, die gleichfalls auf das Weiterleben einer lokalen romanischen Bevölkerungsgruppe bis in das 7. Jh. schließen lassen. Es ist dies u.a. ein Paar von Bronzearmreifen spätantiker Form, während Waffen oder vollständige Gürtelgarnituren, die für bajuwarische Krieger kennzeichnend waren, fehlen.

Für die romanischen Siedlungsgebiete gibt es ganz spezifische Trachtobjekte und Grabbräuche, die sich von denen der Bajuwaren deutlich unterschieden. Bestattung dieser Art treten im Inntal mit besonderer Häufung im Raum Innsbruck und im anschließenden Mittelgebirge auf. Obwohl gänzlich freigelegte spătantike Friedhöfe noch fehlen und häufig nur einzelne Gräber oder Fundstücke aus einem Grăberfeld bekannt sind, lassen sich viele dieser Funde einer romanischen Volksgruppe zuordnen. Dies vor allem dann, wenn es sich um die Gruft einer kirchenstiftenden bzw. einflußreichen Familie wie in der frühchristlichen Kirche von Ampaß oder um die Familiengräber in eigenen Memorialräumen von Kirchen des 7. Jhs. wie in Wattens und in Münster handelt.

\footnotetext{
${ }^{25}$ Lippert 1989, S. 72.

${ }^{26}$ Lippert 1993, S. 11-14.
} 
In romanischen Frauenbestattungen kommen zunächst bandförmige, später gegossene Armreifen mit perlverzierten oder profilierten, kolbenförmigen Enden vor. Sie erinnern an romanische Armringformen aus getriebenem Blech Pannoniens und Noricums (z.B. Zirl - Martinsbühel - Abb. 10: 13, 14, 15). Ähnliches gilt auch für eine Stilusnadel mit laternenartig durchbrochenem Schaft aus Innsbruck - Pradl, die auf Vorbilder aus anderen romanisch besiedelten Gebieten zurückzuführen ist. Möglicherweise sind diese südostalpinen Schmucktypen mit den um 600 vor den Slawen ins Puster-, Eisack- und Wipptal flüchtenden Romanen aus Binnennorikum in Verbindung zu bringen. Jedenfalls wird die Brennerfurche noch im 8. Jh. südlich wie nördlich des Passes als Nuhrital bzw. als Vallis Noricana bezeichnet ${ }^{27}$.

\section{BAJUWARISCHE AUFSIEDLUNG DES INNTALS NACH DEN ARCHÄOLOGISCHEN FUNDEN}

Die bedeutendste Fundstelle für das Inntal in der Bajuwarenzeit sind das Reihengräberfeld und die Kirche von Pfaffenhofen (Abb. 3B). Der Ort liegt auf einem Schwemmkegel am südlichen Talrand des Inns. Zunächst stand hier eine frühchristliche Kirche aus dem 5. Jh.. Sie besaß einen rechteckigen Saal mit freistehender Priesterbank (Abb. 3C) und Chorschranken im höher liegenden Presbyterium ${ }^{28}$. Die Kirche (Abb. 3A, 3B) war $18,1 \times$ ca. $8 \mathrm{~m}$ gro $3^{29}$. Die älteste Bauphase ist durch die ursprünglich mit einem erhöhten Sitz im Scheitel (Kathedra) versehene Priesterbank belegt $^{30}$. Die Ausdehung des einst mit Holzschranken umgebenen, erhöhten Presbyteriums war an einem Mauerfundament erkennbar. Von Reliquienkammer und Altar konnten keine Spuren entdeckt werden ${ }^{31}$. Die bajuwarischen Grundherrn haben diese Kirche erneuert und zwei gemauerte Grüfte angelegt (Abb. 3A). Gruft II lag etwa in der Mitte des südlichen Kirchenschiffes in West-Ostrichtung an der Langhausmauer, Gruft I unmittelbar östlich der älteren Gruft II. In Pfaffenhofen haben wir den Sippenfriedhof einer adeligen Familie. Der Wiederbauer der Kirche fand in Gruft II im letzten Viertel des 7. Jhs. seine letzte Ruhestätte, sein Nachfolger wurde in Gruft I bestattet. Mit dieser in Gruft I aufgedeckten Bestattung fassen wir die jüngste Phase der Pfaffenhofener Gräber aus der Zeit von 720 bis 750 . Zeitlich zwischen diese beiden Bestattungen liegt das reich ausgestattete Grab 25, möglicherweise der Sohn oder Bruder des Toten aus Gruft I. Von den ungefähr 30 Gräbern in Pfaffenhofen konnten einige als Frauengräber identifiziert werden, wobei jedoch nur sehr wenige besser ausgesttatet waren ${ }^{32}$. Vor der nördlichen Langhauswand

\footnotetext{
${ }^{27}$ Lippert 1989, S. 71-73.

${ }^{28}$ Lippert 1990, S. 212.

${ }^{29}$ Glaser 1997, S. 151.

${ }^{30}$ Sydow 1990, S. 27.

${ }^{31}$ Glaser 1997, S. 151.

${ }^{32}$ Plank 1964, S. 131-133.
} 


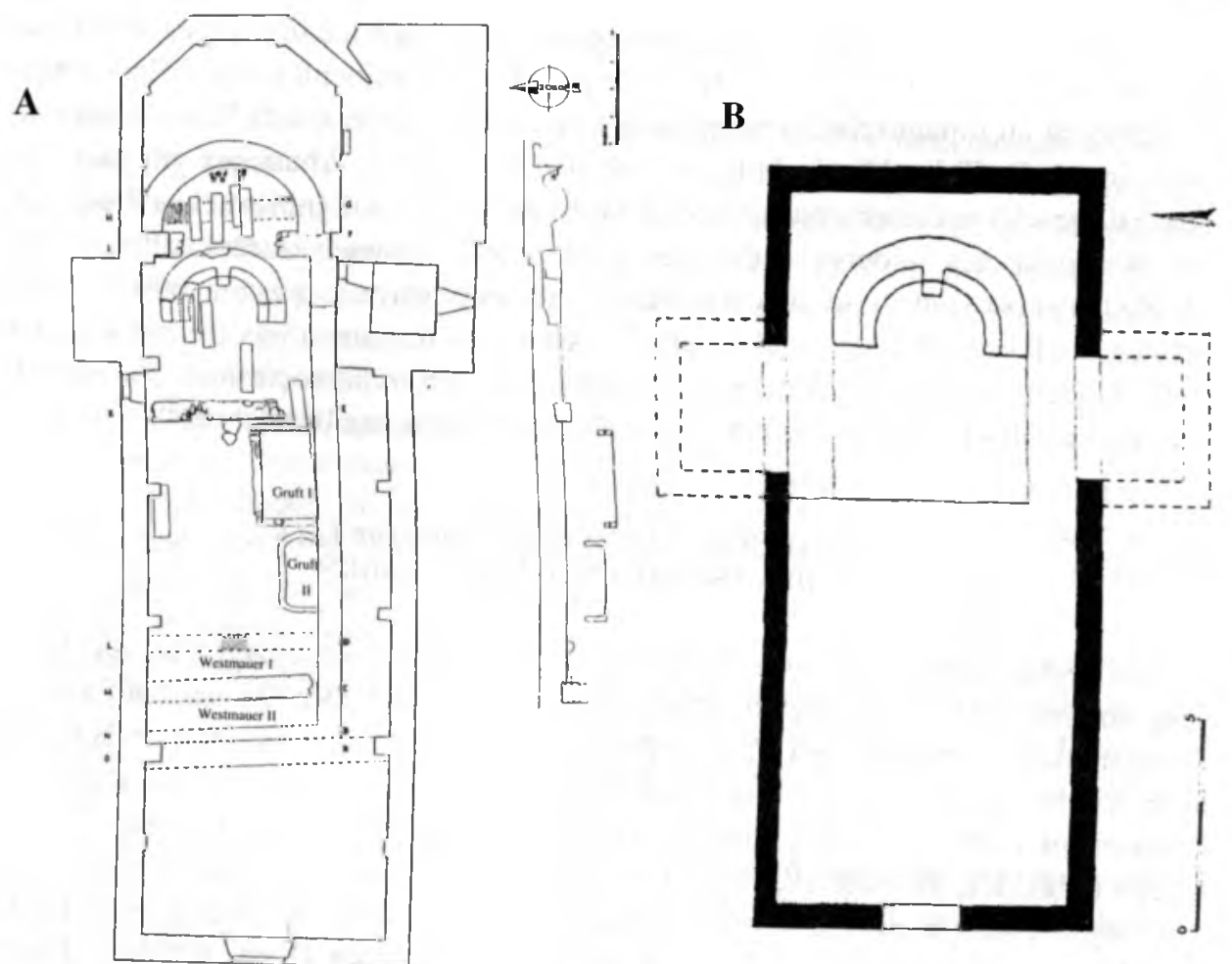

\begin{tabular}{ll}
\multicolumn{2}{l}{ Verzeichnis der Mauerstärken } \\
Priesterbank & $1,00 \mathrm{~m}$ \\
Chorschrankenmauer & $0,60 \mathrm{~m}$ \\
Westmauer I & $0,80 \mathrm{~m}$ bis $0,90 \mathrm{~m}$ \\
Nordmauer & $0,65 \mathrm{~m}$ \\
Südmauer & $0,70 \mathrm{~m}$ \\
Westmauer II & nicht untersucht \\
Apsis & $0,80 \mathrm{~m}$ \\
Gruft I & bis $0,40 \mathrm{~m}$ \\
Gruft II & $0,30 \mathrm{~m}$
\end{tabular}

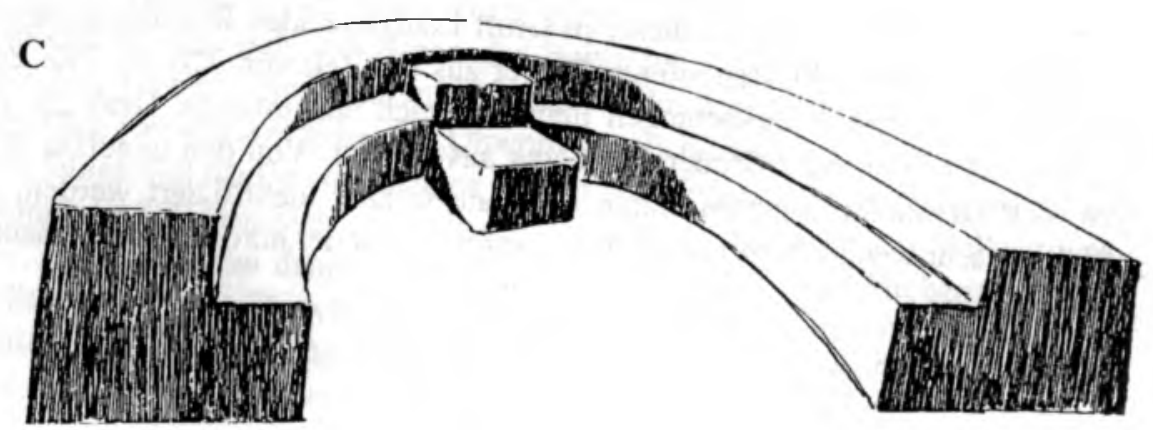

Abb. 3. Pfaffenhofen.

A - Pfarrkirche, Übersichtsplan (nach Kaltenhauser 1964); B - rekonstruierter GrundriB der Kirche (nach Plank 1972); C - die
Priesterbank während der Priesterbank während der zweiten Phase mit vorgebauter Stufe - Rekonstruktion (nach Kaltenhauser 1964) 
des ältesten Kirschenbaues ist Grab III gelegen (Abb. 3A). Es konnte nicht vollständig freigelegt werden. Es handelte sich um eine Frau, die im Alter von 30-40 Jahren verstarb. Beigabe wurde keine geborgen. Antropologisch unterscheidet sich diese Tote deutlich vom Mann aus Gruft II. Gewisse Ähnlichkeiten ließen sich in Schädelform und Physiognomie mit spätrömischen Skelettfunden in Weißling (Bayern) feststellen ${ }^{33}$. Unmittelbar östlich und westlich der Kirche wurden beigabenlose Bestattungen einer spätrömischen (romanischen) Bevölkerungsgruppe gefunden. Das Grabfeld südlich der Kirche war wahrscheinlich durch die moderne Verbauung zerstört. Es wurde von etwa 600 bis an das Ende des 7. Jhs. belegt. Im Westen lagen die Bestattungen in streng geordneten Reihen eng beisammen. Hier traten auch auffallend viele Kriegerbeisetzungen, z.T. mit wertvoller Ausstattung auf, sowie im Grab 32 die Bestattung einer wohlhabenden Frau in reich geschmückter Tracht. Im Ostteil der Gräberzone lagen die Gräber in lockeren Reihen weit auseinander und enthielten eher einfache oder ärmliche Beigaben. Beide Teile des freigelegten Gräberfeldes enthielten Bestattungen aus allen Belegungsphasen, also des gesamten 7. Jhs. Es ist somit zu vermuten, daß die soziale Oberschicht einer bajuwarischen Sippe und ihr Gefolge getrennt im Gräberfeld bestattet wurde. Wahrscheinlich waren zumindest die früheren Häupter der Sippe schon bei ihrer Ankunft um 600 - gleich den einheimischen Romanen - katholische Christen, was aus der Anlage ihrer Grabstätten in allernächster Nähe zur frühchristlichen Kirche hervorgeht. Die bronzene Riemenzunge einer ihrer Angehörigen (Grab 31, 2 Drittel 7. Jh.) ist mit einem eingeritzten Kreuzzeichen versehen ${ }^{34}$. Die nachweisbare Belegung des Reihengräberfeldes von Pfaffenhofen setzt um die Mitte des 7. Jhs. ein. Dieser Zeit gehört Grab 12 (mit damaszierter Spatha und Sax mit langer Griffangel) an (Abb. 6: 14, 15). Eine Spatha und Sax mit langer Griffangel wurden dem Toten von Grab 11 mit ins Jenseits gegeben (Abb. 6: 4). Dies geschah wohl zwischen 660-690. Ungefăhr zur selben Zeit kam Bestattung 22 (eine Spatha mit streifentauschierter Knaufplatte und Parierstange und eine kleine Bronzeschnalle mit mitgegossenem Tierornament im Still II) in die Erde (Abb. 7: 1-4). Grab 17 mit tierstilverzierten Saxscheidennieten lassen sich in die zweite Hälfte des 7. Jahrhunderts datieren (Abb. 6: 17-19). Der Sax (Abb. 6: 17) besitzt eine Parallele in Zirl (Abb. 10: 2). Die nächste zeitliche Stufe stellt Pfaffenhofen Grab 29 dar. Der Sax (Abb. 7: 11) und der hochkalottenförmige Schildbuckel (Abb. 7: 13) datiert in das letzte Drittel des 7. Jahrhunderts. Als jüngste Bestattung in Pfaffenhofen ist Grab 25 azusehen (Abb. 7: 7-9). Es enthielt wabenplattierte Gürtelbeschläge mit Almandineinlagen. Dieses Grab ist um oder kurz nach 700 zu datieren $^{35}$.

Gemeinhin werden im bayerischen Siedlungsraum um oder kurz nach 700 die am Rande der Siedlungen angelegten Friedhöfe aufgelassen, Kirchen im Ortskern angelegt und die Bestattung um die Kirchen herum vorgenommen. In Pfaffenhofen

\footnotetext{
${ }^{33}$ Lippert 1990, S. 215.

${ }^{34}$ Lippert 1990, S. 212.

${ }^{35}$ L. Plank 1964, S. 130.
} 


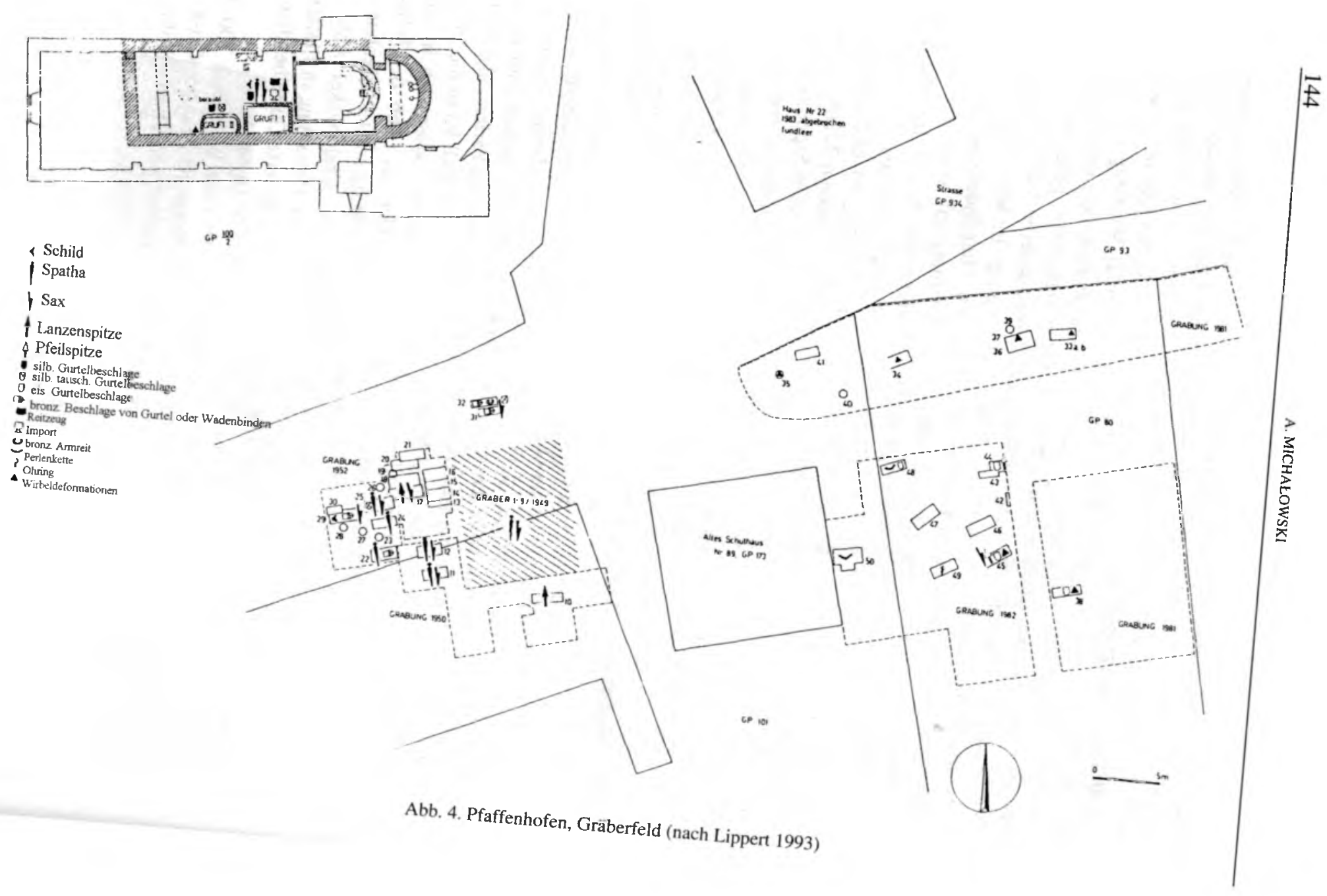




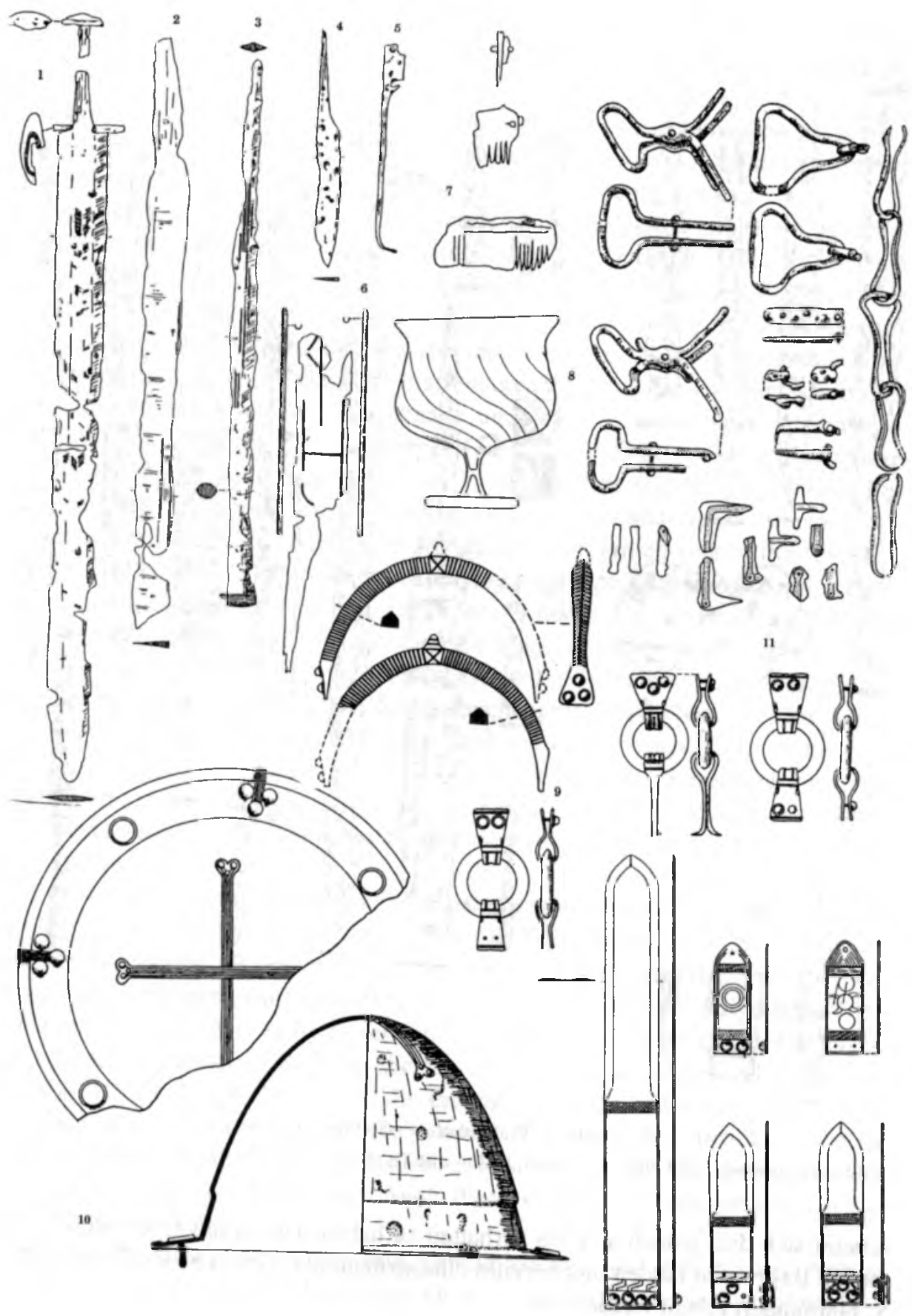

Abb. 5. Pfaffenhofen, Gruft I - Grabfunde (nach Plank 1964) 


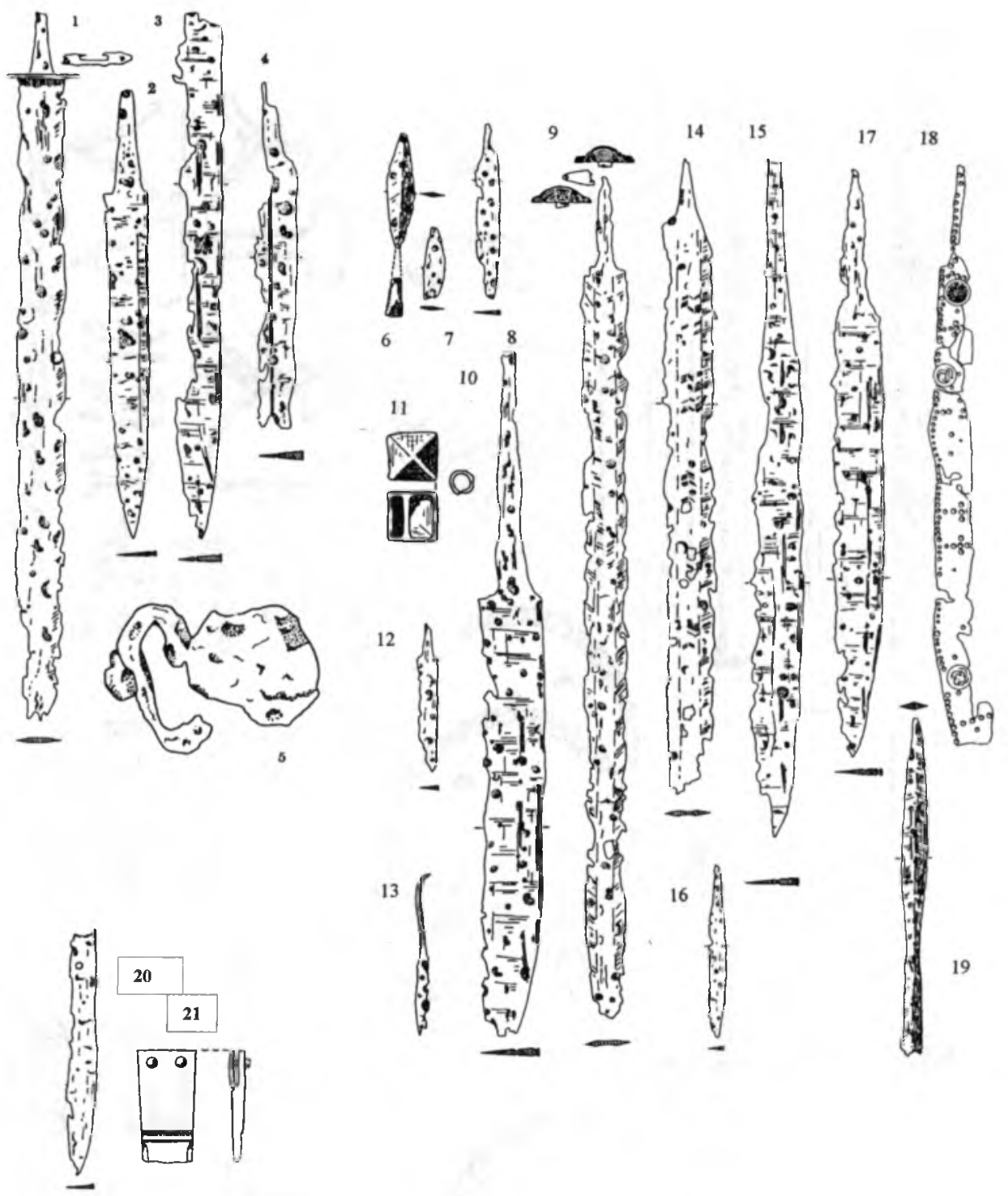

Abb. 6. Pfaffenhofen - Grabbeigaben

I-5 - Grab 1-9; 6-8 - Grab 10; 9-13 - Grab 11; 14-16 - Grab 12; 17-19 - Grab 17; 20, 21 - Gruft II (nach Plank 1964)

scheint sich dies jedoch anderes verhalten zu haben. Die in das Oberinntal gekommenen Bajuwaren fanden hier bereites eine spätantike Steinkirche vor ${ }^{36}$, die wohl im 5. Jahrhundert erbaut worden war. 
Durch die Möglichkeit der zeitlichen Eingliederung der Funde von Pfaffenhofen können Querverbindungen zum übrigen, parallelen Fundmaterial Nordtirols hergestellt werden. An den Beginn der tirolischen Reihengräberfunde können leider nur Einzelfunde gestellt werden. Die von verschiedenen Orten stammenden Armreifen sind chronologisch nicht empfindlich; sie gehören alle in das 7. Jahrhundert, können innerhalb dieses Zeitraumes jedoch nicht genauer eingeordnet werden.

Die Spatha und der Sax finden sich häufig in Männergräbern der Reihengräberfriedhöfe in Telfs und Pfaffenhofen. Die in Telfs - St. Georgen bisher gefundenen Waffen (Abb. 9: 6-10) weisen in die Endphase der durch Beigaben datierbaren Reihengräberzeit und sind nach 700 anzusetzen. St. Georgen und Gruft I in Pfaffenhofen (Abb. 5) sind die Repräsentanten der jüngsten Phase. Eine besonders schöne Spatha (Abb. 6: 9) ist aus Grab 11 in Pfaffenhofen erhalten. Sie war damasziert und besaß eine streifentauschierte Parierstange und einen silbertauschierten Schwertknauf. Der mitgefundene Sax mit langer Griffangel erlaubt uns eine Zuweisung dieser Bestattung in die zweite Hälfte des 7. Jhs. Ein Sax mit der zugehörigen Lederscheide, die mit gegossenen verzierten Bronzeknöpfen und vielen kleinen Bronzenieten mit halbkugeligen Nietköpfen beschlagen war, erhielt sich in Pfaffenhofen in Grab 17 (Abb. 6: 17, 18). In diesem Grab lag auch eine Lanzenspitze mit schmalem Blatt und achtkantiger Tülle (II. Hälfte des 7. Jhs. - Abb. 6: 19). Dem Formenschatz der ersten Hălfte des 7. Jhs. gehören die Flügellanzenspitze aus Matrei a.Br. Mühlbachl (Abb. 10: 17) und die Kurzsax (Abb. 10:16) aus Ötz an. Diese Funde schließen sich an die bisher besprochenen Reichengräberfunde lückenlos $\mathrm{an}^{37}$. Eine vielteilige Gürtelgarnitur wurde in einem Grab am Galgenbühel, Gem. Natters gefunden. Sämtliche Teile dieser Gürtelgarnitur zeigen auf der Schauseite ein Ornament verschlagener Tierleiber im Tierstil II. Diese Ornamente werden von Silberstreifen eingefaßt. Das Grab von Natters läßt sich dem letzten Drittel des 7. Jahrhunderts zuweisen.

Eine andere Art von Gürtelabschlägen ist die aus Bronze hergestellte Garnitur aus Grab 29 von Pfaffenhofen (Abb. 7: 12). Die Schnalle mit dem glatten Schilddorn, der zugehörige Gegenbeschlag, eine große Rückenplatte, die zwei Riemenzungen und die übrigen Gürtelbeschläge sind, abgesehen von den halbrunden Nietköpfen mit Perlrandbasis, völlig unverziert. Zwei Stücke einer derartigen Gürtelgarnitur konnten im zerstörten Reihengräberfeld von Unterlangkampfen geborgen werden (Abb. 10: 18-22). Während man die Erzeugung dieser Teile eines Schwertgürtels bisher den Langobarden zuschrieb, wurde nun auch die Ansicht vertreten, sie wären von der weiterlebenden romanischen Restbevölkerung Norditaliens und des östlichens Alpenraumes hergestellt. Auch diese Gürtelgarnituren gehören in die zweite Hälfte des 7. Jhs.

Eine unvollständig erhaltene Gürtelgarnitur stammt aus dem bei der Anlage eines Kabelgrabens weitgehend zerstörten Grab 31 von Pfaffenhofen. Zwei ihrer Be-

${ }^{37}$ Plank 1964, S. 133, 134. 

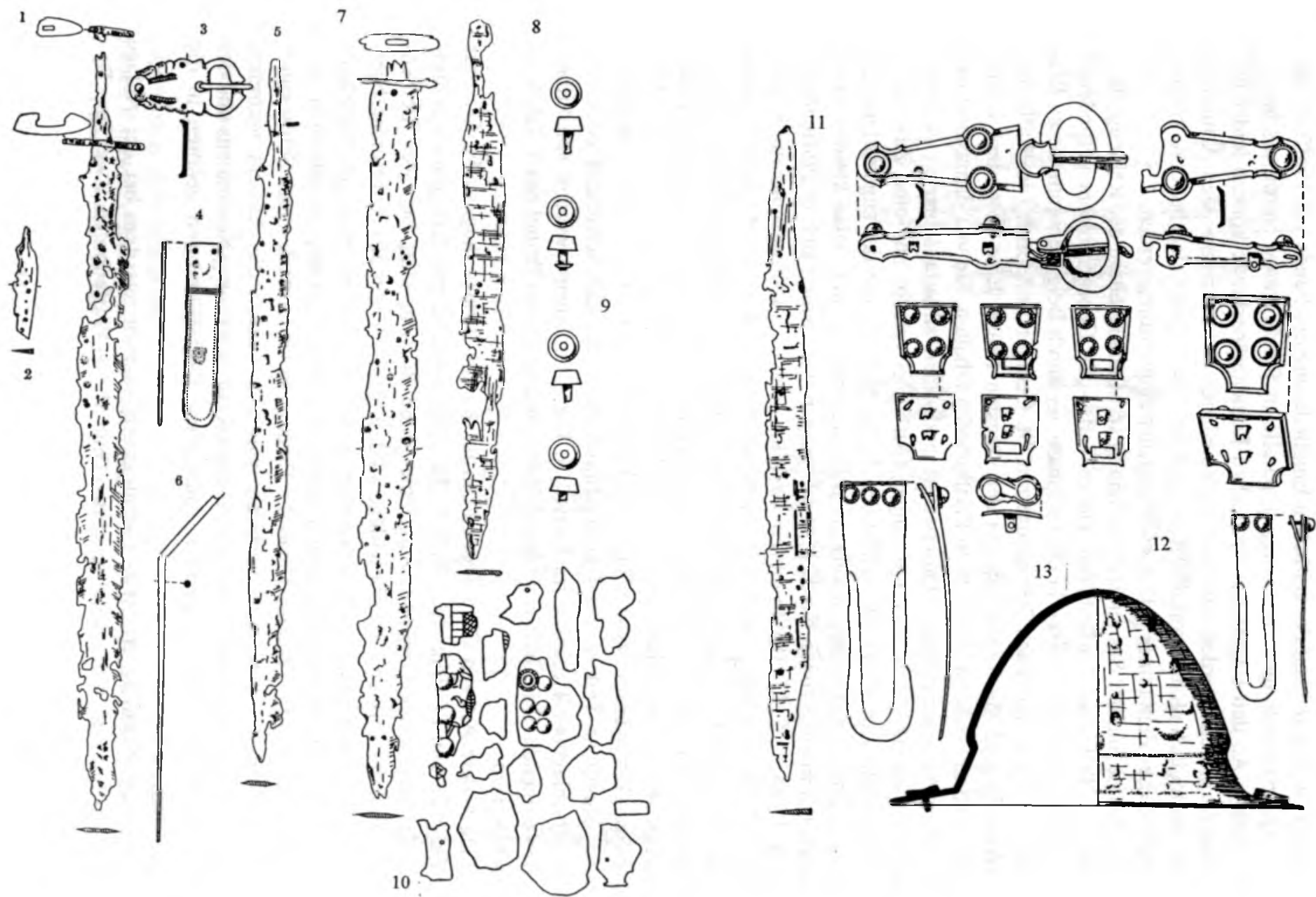
A
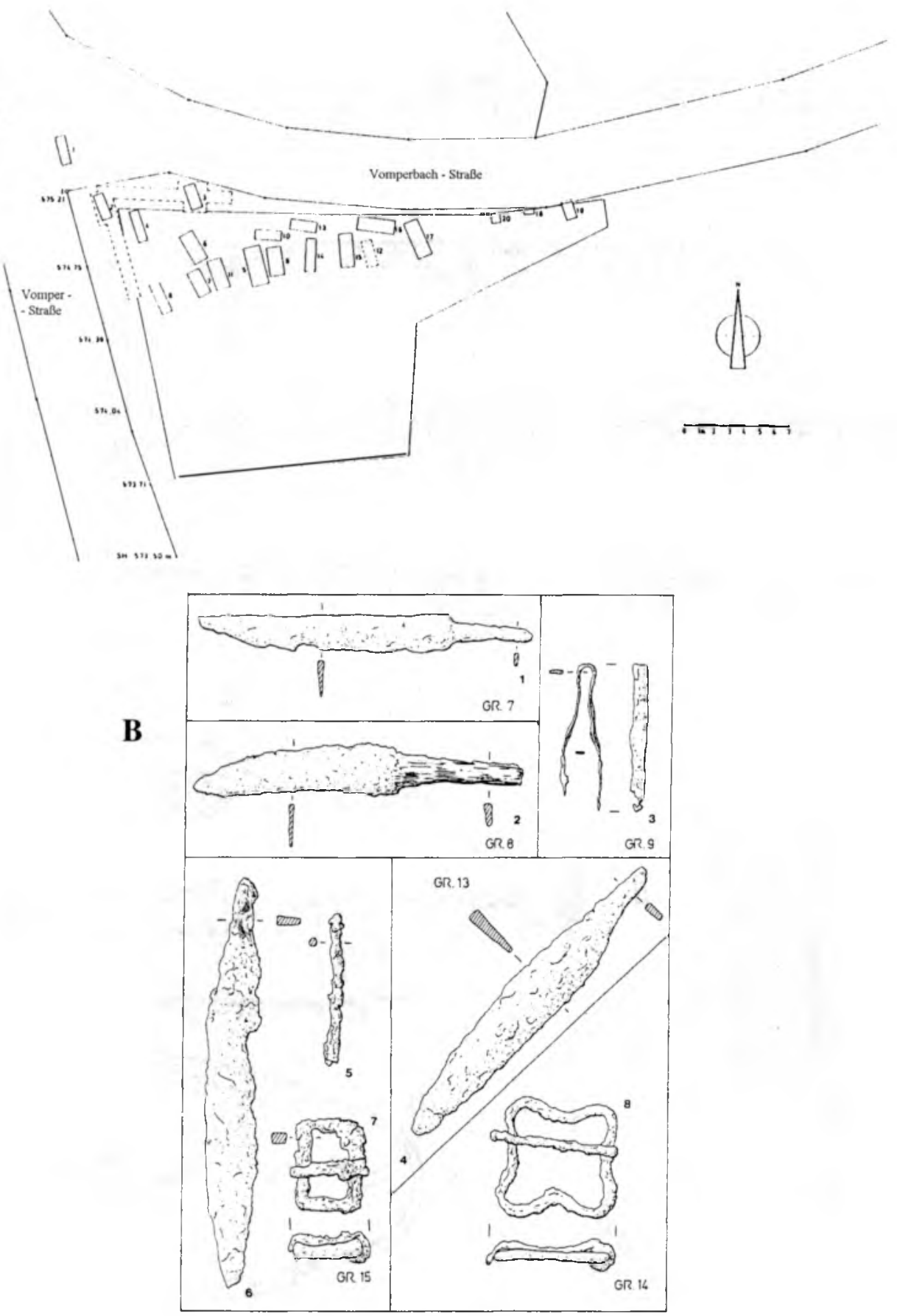

Abb. 8. Terfens. A - die bisher freigelegten Gräber; B - Grabbeigaben (nach Lippert 1993) 

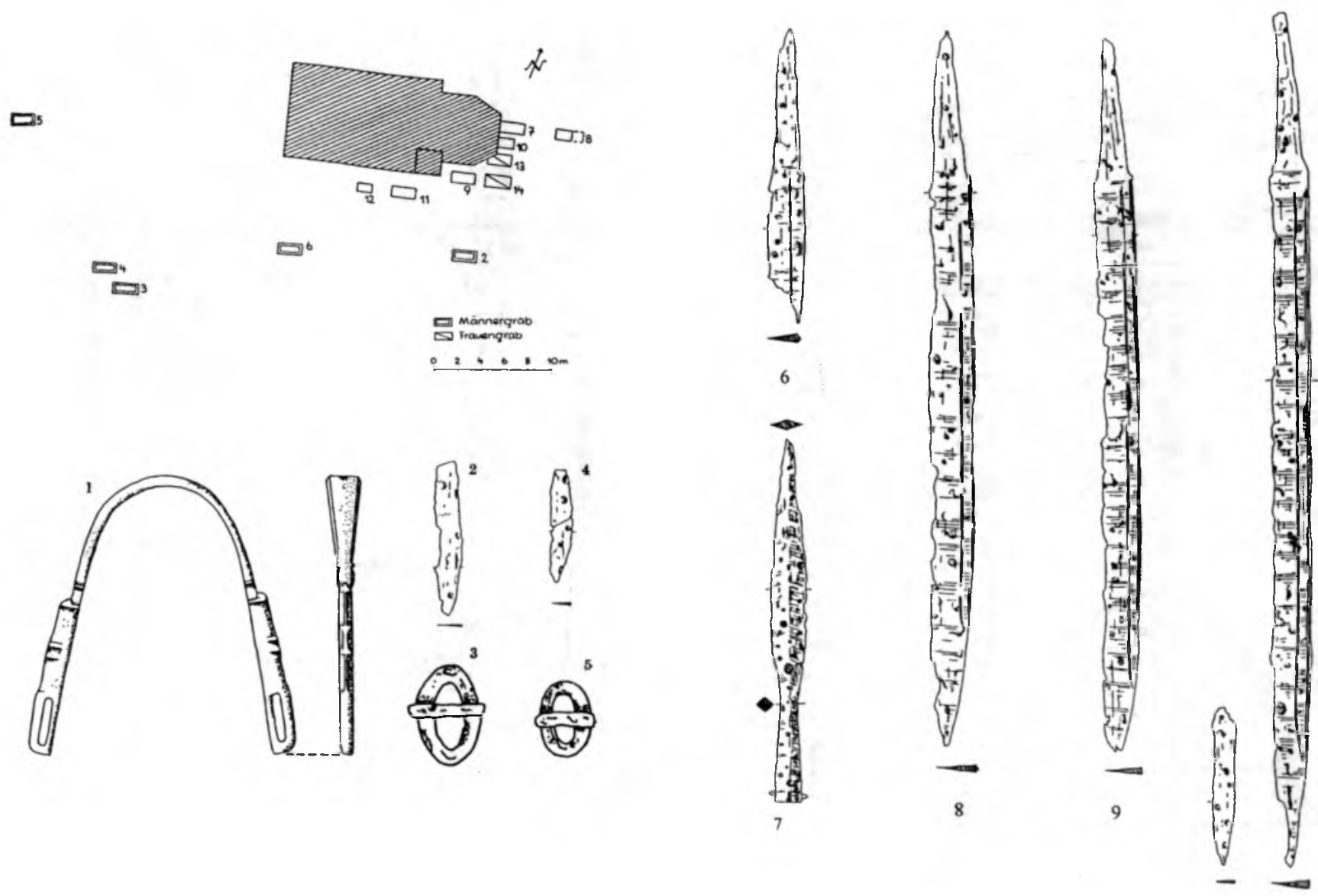

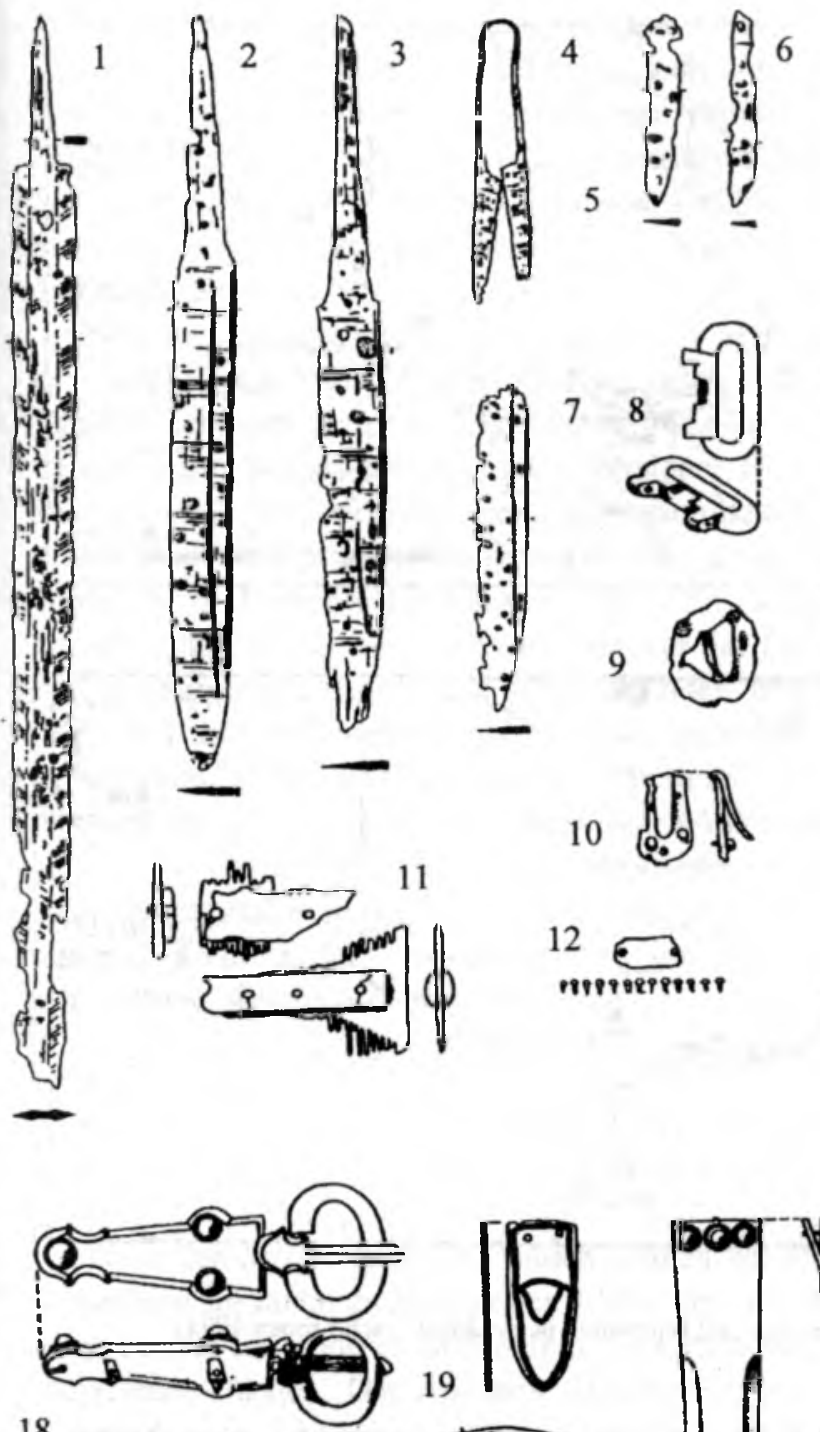

18

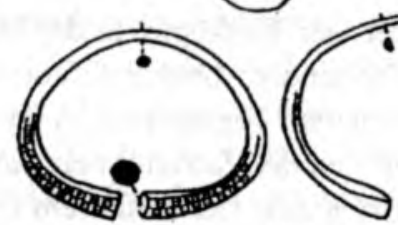

21

20
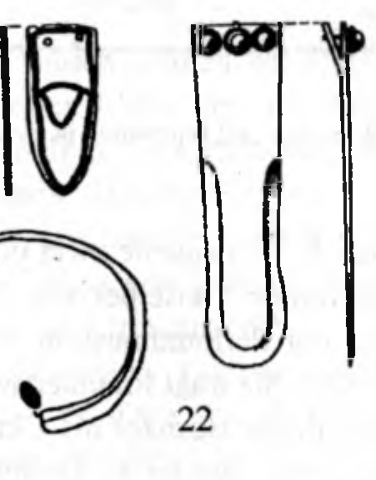

Abb. 10. Grabfunde

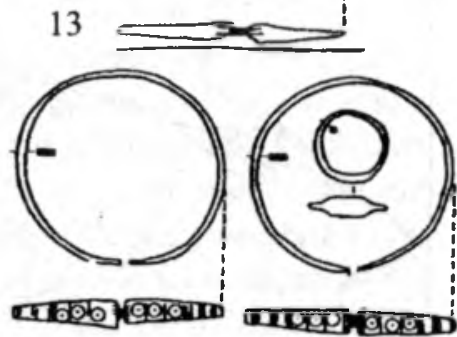

14

15

16

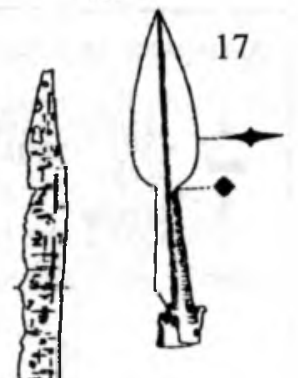

1-12 - Zirl, 13-15 - Zirl - Martinsbühel, 16 - Ötz, 17 - Mühlbachl bei Matrei a.B, 18-22 - Unterlangkampfen, 23 - Weerberg, 24 - Innsbruck-Pradl (nach Plank 1964) 

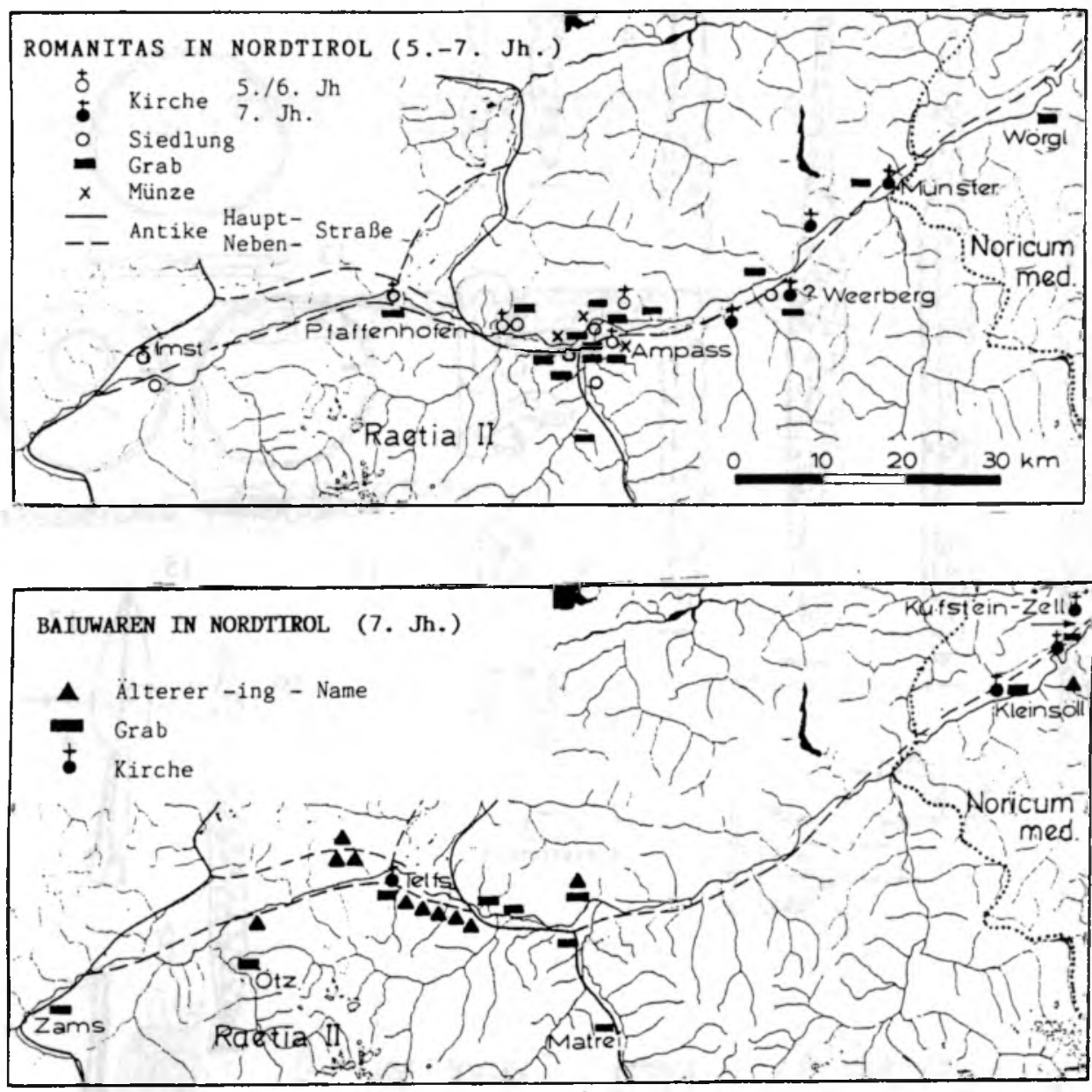

Abb. 11. Fundorte zu Romanen und Bajuwaren in Nordtirol (nach Lippert 1993)

schläge aus Bronze zeigen auf der Schauseite zwei oder vier Tierköpfe. In der Mitte der Beschläge sind die gekrümmten Tierleiber von Perlbändern begleitet. Von den beiden zugehörigen, ebenfalls mit Perlrandmustern verzierten Riemenzungen ist die größere die weitaus bedeutendere. Sie trägt im untersten Teil des Zierfeldes ein Kreuz und weist dadurch ihren ehemaligen Besitzer als Christen aus. Der in diesem Grab gefundene Sax mit langer Griffangel datiert die Bestattung in die Zeit kurz nach 650.

Die kostbarste Bestattung aus dem Inntal wurde innerhalb von Gruft I in der Pfaffenhofener Kirche aufgedeckt (Abb. 5). Gefunden wurden hier Spatha und Sax, Lanzenspitze aus Eisen mit schmalem Blatt, deren Tülle mit einem gerillten Silberblechband eingefaßt ist. Auch der Schildbuckel mit kugeliger Kalotte war mit kreuz- 
förmig übereinandergelegten Sielberbändern verziert, mit Silberblechstreifen eingefaßt und mit Silbernieten mit Holzschild befestigt. Durch die Beigabe streifentauschierter Nietensporen, dreier versilberter Bronzeringe mit Riemenzwingen von Zaumzeug und Sattel wird der Tote als begüterter Reiter ausgewiesen. Ein weiteres Reitergrab aus der Zeit um 700 wurde in Telfs - St. Georgen bei modernen Grabungsarbeiten zerstört, doch es blieb ein bronzener Schleifensporn mit eisernem Stachel erhalten (Abb. 9: 1).

Von den wenigen im Inntal gelegenen Frauengräbern lassen sich die Beigaben aus Grab 32 von Pfaffenhofen, zwei Riemenzungen aus Bronze mit eingraviertem Tierornament und der zugehörige Armreif aus Bronze mit keulenförmig verdickten Enden, deren Schauseiten mit kreuzförmigem Ornament verziert sind, sowie ein Paar einfacher Schleifenohrringe aus Bronze und einer aus 45 Glaspasteperlen verschiedener Färbung zusammengesetzten Halskette bestehenden Grabbeigaben des Grabes 14 im Reihengräberfeld von Telfs - St. Georgen in die zweite Hälfte des 7. Jhs. einreihen. Etwas besser ausgestattet war das Frauengrab von Arzl, in dem sich drei Armreife aus Bronze mit offenen Enden und unterschiedlicher Verzierung, Glas- und Silberblechperlen und ein Bommelohring fanden. Diese Schmuckstücke treten schon ab dem frühen 7. Jh. in Gräbern auf. Aus einem Frauengrab dürfte die Nadel mit einer stilisierten Raubvogelfigur (Adlerfigur? siehe Lippert 1989, S. 73) aus Bronze von Kirchbühel St. Peter in Weerberg stammen (Abb. 10: 23). Da diese Nadel wohl noch dem 6. Jh. angehört, stellt sie den ältesten Fund des frühen Mittelalters in Nordtirol dar ${ }^{38}$. Wahrscheinlich war sie aber Haarschmuck einer romanischen Dame, welche hier bestattet wurde ${ }^{39}$.

\section{BAJUWARISCHE AUFSIEDLUNG DES INNTALS NACH DEN NORDTIROLER ORTSNAMEN}

Nach den archäologischen Funden können wir feststellen, daß die bajuwarische Besiedlung im Inntal zu Beginn des 7. Jhs. einsetzt. Aus dem 6. Jh. gibt es nur einzelne Funde. Ein anderes Bild liefern die Ortsnamen, die z.T. bis in das 6. Jh. zurückreichen dürften. Die Annahme Heubergers, die ältesten germanischen Siedler Nordtirols seien Alamannen gewesen, werden hinfällig, wenn wir mit der baierischen Landnahme in die Zeit kurz vor 590 rücken. Frühnennungen überliefern uns eine Reihe von Ortsnamen germanischen und romanischen Ursprungs: Radfeld, Pirchnawanach, Chaofstein, Episas, Lantekamphia, Prixina, Quantula, Prislech, Oriano und Cellola $^{40}$. Die frühbajuwarischen -ing-Orte wie: Inzing, Hatting, Polling, Flaurling, Leiblfing, Mieming oder Haiming enthalten sehr alte Personennamen (die patronomi-

\footnotetext{
${ }^{38}$ Plank 1972, S. $19,20$.

${ }^{39}$ Lippert 1989, S. 73.

${ }^{40}$ Plank 1964, S. 134-136.
} 
schen Ortsnamen). Hatting z.B. bedeute soviel wie „zur Siedlung der Leute des Hatto". Alle angefürten Ortsnamen entsprechen der ältesten germanischen Namensschicht des 6. und 7. Jhs., vor allem der Zeit zwischen 550-650. Sie treten in den kirchlichen Schenkungsurkunden des 8 . oder 9. Jhs. kaum mehr auf. Wer die Namensgeber dieser frühen Siedlungen mit der Endung auf -ing waren, ist nicht sicher zu sagen ${ }^{41}$.

Im Raum von Hötting bis Haiming begegnen uns -ing-Orte und Frühnennungen von Orten, wobei es sich hier allerdings durchwegs um vorderdeutsche Siedlungsnamen (Taurane, Wiltina, Wattenes, Volares usw.) handelt. Ob die -ing-Orte dieses Raumes eine eigene Phase bei der Landnahme darstellen, muß offen bleiben. Wenn wir die Lage der Fundorte frühmittelalterlicher Gräber oder Einzelfunde und ihre Situation zum römischen Straßennetz betrachten, zeigt sich, daß ein großer Teil dieser Plätze unmittelbar an den Römerstraßen oder nicht weit entfernt von diesen liegen. Teilweise ist dies sicher auch dadurch bedingt, daß es in diesem Gebiet nur begrenzte Möglichkeiten für die Anlage von Straßen und Siedlungen gab ${ }^{42}$.

Die -hofen-Ortsnamen im Oberinntal sind wahrscheinlich erst um 700 oder danach entstanden und sind mit dem Aufkommen einer neuen Herrschaftsstruktur zu erklären. Namen wie Pfaffenhofen (Papo-hofen?), Oberhofen, Eigenhofen, Hof (bei Hatting) und Baierhof weisen auf adelige Herrenhöfe hin, um die sich erfahrungsgemäß zunächst keine oder nur kleine Siedlungen, also Hofgruppen, bildeten. Übrigens gibt es, abgesehen vom Namen des heutigen Weilers Baierhof, noch eine weitere Hofgruppe mit der ethnischen Namenswurzel: es ist dies Baierdorf, das oberhalb von Telfs an der Wegstrecke zum Paß in die Leutaschch liegt ${ }^{43}$.

Ebenso wenig wie für das langobardische Gebiet kann für den tiroler Raum angenommen werden, daß bei der bajuwarischen Landnahme die alteingesessenen Romanen ausgerottet worden wären, was ja auch aus den urkundlichen Nennungen von Romanen noch im 9. Jahrhundert ersichtlich ist ${ }^{44}$.

\section{KURZE ZUSAMMENFASSUNG. KOEXISTENZ DER ROMANEN UND BAJUWAREN IM INNTALGEBIET}

Die romanische Besiedlung im Inntal war seit dem 5. Jh. im allgemeinen nicht besonders dicht. Dies trifft jedoch nicht für die Seitentäler im westlichen Tirol oder für das Wipptal und den Raum Insbruck zu. Auch die Zone zwischen Innsbruck und der Linie Habach-Brixlegg-Zillermündung war von Romanen ziemlich gleichmäßig besiedelt. Diese romanischen Siedlungsenklaven wurden von den landnehmenden Bajuwaren im 7. Jh. weitgehend respektiert ${ }^{45}$. Die Bajuwaren ließen sich in den siedlungsarmen Landschaften des oberen Inntals nieder. An manchen Stellen, wie in

\footnotetext{
${ }^{41}$ Lippert 1990, S. 220.

${ }^{42}$ Plank 1964, S. 134-136.

${ }^{43}$ Lippert 1990, S. 221.

${ }^{44}$ Plank 1964, S. 134, 135.

${ }^{45}$ Lippert 1989, S. 75.
} 
Pfaffenhofen, ist auch ein Zusammenleben von Bajuwaren und Romanen belegbar ${ }^{46}$. Die archäologischen, geschichtlichen und namenskundlichen Überlieferungen zeichnen ein übereinstimmendes Bild. Um 600 wurde das damals siedlungsarme Gebiet zwischen Zirl und Telfs - Pfaffenhofen durch eine bajuwarische Grundherrenfamilie aus dem Geschlecht der Huosi erschlossen und systematisch besiedelt. Dieses Landnahmegebiet entstand am Ende des 7. Jhs. als ein abgegrenzter Gau, der unter der Herrschaft der inzwischen weiter aufgestiegenen Huosi-Familie stand. Die führenden Mitglieder dieser Familie hatten ihren Herrenhof vermutlich in Pfaffenhofen. Es ist nicht auszuschließen, ja es ist sogar sehr wahrscheinlich, daß sich zumindest die Oberschicht der bajuwarischen Kolonisatoren mit einheimischen romanischen Familien verbanden. Darauf deutet beispielsweise das offenbar beigabenlose Fraugrab, das den Männergräbern im Kirchenschiff gegenüber lag, hin ${ }^{47}$.

In manchen, sonst typisch romanischen Gräberfeldern ist eine gewisse Anpassung an die bajuwarischen Zuwanderer festzustellen. Für Romanen und Bajuwaren ist also eine friedliche Koexistenz anzunehmen. Ein Zusammenleben von Angehörigen beider Volksgruppen kam durchaus vor. Dies aber fiel wieder umso leichter, als die ins Inntal einwandernden Bajuwaren wahrscheinlich schon mit dem Christentum vertraut waren. Bajuwarische Adlige mit ihren Gefolgsleuten hingen gleich nach Herzogshaus schon früh dem neuen Glauben an. Im Gegensatz zu den Langobarden in Italien, die zuerst der arianischen Richtung des Christentums angehörten, waren die Bajuwaren von vornherein katholisch, gleich der einheimisch-romanischen Bevölkerung. Auch die durch die Herrschaftsbildung der Bajuwaren in ganz Tirol entstandene Konsolidierung trug sicher zu einem friedlichen Nebeneinander der beiden Völker bei. Die Abwehr gegen Alamannen, Langobarden und Slawen war eine zumindest politische Identität von Romanen und Bajuwaren ${ }^{48}$.

Die romanische Volksgruppe bestand noch eine Weile im Inntal weiter. Durch die zahlenmäßig größere germanische Aufsiedlung, verbunden mit weiteren bajuwarischen Kolonisationsschüben, wurde sie wahrscheinlich ab dem frühen 8 . Jh. kulturell und vor allem sprachlich assimiliert.

\section{LITERATUR}

Bierbrauer V.

1985 Das Reihengräberfeld von Altenerding in Oberbayern und die bajuwarische Ethnogenese eine Problemskizze, ,Zeitschrift für Archäologie des Mittelalters”, Jg. 13, S. 7-25.

1994 Langobarden, Bajuwaren und Romanen im mittleren Alpengebiet in 6. und 7. Jahrhundert. Siedlungsarchäologische Studien zu zwei Überschichtungsprozessen in einer Grenzregion und zu den Folgen für die "Alpenromania”, (in:) Grenzen und Grenzregionen, Saarbrücken, S. 147-178.

\footnotetext{
${ }^{46}$ Lippert 1989, S. 75.

${ }^{47}$ Lippert 1990.

${ }^{48}$ Lippert 1989, S. 76.
} 
Di et z K.

1995 Okkupation und Frühzeit, (in:) Die Römer in Bayern, Stuttgart, S. 18-99.

F i s cher T.

1995 Spätzeit und Ende, (in:) Die Römer in Bayern, Stuttgart, S. 358-404.

Fis cher T., Geisler H.

1988 Herkunft und Stammesbildung der Baiern aus archäologischer Sicht, (in:) Die Bajuwaren. Von Severin bis Tassilo 488-788, Rosenheim - Mattsee, S. 61-68.

$\mathrm{Gl}$ a s e r F.

1997 Frühes Christentum im Alpenraum. Eine archäologische Entdeckungsreise, Darmstadt. $\mathrm{He}$ uberger R.

1932 Rätien im Altertum und Frühmittelalter. Forschungen und Darstellung, Bd. I, Innsbruck.

$\mathrm{K}$ alt en hauser $\mathrm{G}$.

1964 Die Aufdeckung der frühchristlichen Kirche zu Pfaffenhofen in Tirol, „Veröffentlichungen des Museum Ferdinandeum", Bd. 44, S. 75-98.

$\mathrm{K}$ rinzinger $\mathrm{F}$.

1972 Tirol unter Römischer Herrschaft, (in:) Vor- und Frïhgeschichte im Inntal, Innsbruck, S. 1117.

Lippert A.

1989 Nordtirol in der Spätantike und im frühen Mittelalter, (in:) Frühes Leben in den Alpen, Ausgrabungen und Forschungen des Institut für Ur- und Frühgeschichte der Universität Innsbruck, Innsbruck, S. 69-84.

1990 Die Adelsbestattungen in Pfaffenhofen und die inneralpine Landnahme der Bajuwaren, (in:) ECHO, Beiträge zur Archäologie des mediterranen und alpinen Raumes, Johanes B. Trentini zum 80. Geburtstag gewidmet von seinen Freunden und Verehrern, Innsbruck, S. 209-222.

1993 Der anthropologische Beitrag zu archäologischen Ergebnissen am Beispiel frühmittelalterlicher Gräberfelder im Tiroler Inntal, (in:) Bioarchäologie und Frühgeschichtsforschung, Wien, S. 11-32.

Lot ter F.

1985 Die germanischen Stammesverbände im Umkreis des Ostalpen - Mitteldonau - Raumes nach der literarischen Überlieferung zum Zeitalter Severins, (in:) Die Bayern und ihre Nachbarn, Teil 1, Wien, S. 29-59.

Plank L.

1964 Die Bodenfunde des frühen Mittelalters aus Nordtirol, „Veröffentlichungen des Museum Ferdinandeum", Bd. 44, S. 99-208.

1972 Das frühe Mittelalter in Tirol, (in:) Vor-und Frühgeschichte im Inntal, Innsbruck, S. 18-20. Re inde $1 \mathrm{~K}$.

1988 Herkunft und Stammesbildung der Bajuwaren nach den schriftlichen Quellen, (in:) Die Bajuwaren. Von Severin bis Tassilo 488-788, Rosenheim - Mattsee, S. 56-60.

S y d ow W.

1990 Das frühe Christentum in Nord- und Osttirol nach den archäologischen Zeugnissen, „Tiroler Heimat", Bd. 54, S. 25-51.

Wolf ram H.

1979 Geschichte der Goten: von den Anfägen bis zur Mitte des sechsten Jahrhunderts. Entwurf einer historischen Ethnographie, München.

1985 Ethnogenesen im frühmittelalterlichen Donau- und Ostalpenraum (6. bis 10. Jahrhundert), (in:) Frühmittelalterliche Ethnogenese im Alpenraum, Sigmaringen, S. 97-151. 